\title{
Metabolism of $\left[3-{ }^{-13} \mathrm{C}\right]$ pyrtuvate and $\left[3-{ }^{13} \mathrm{C}\right]$ propionate in normal and ischaemic rat heart in vivo: ${ }^{1} \mathrm{H}$ - and ${ }^{13} \mathrm{C}-\mathrm{NMR}$ studies
}

\author{
Balazs SUMEGI, $§$ Benjamin PODANYI, $\uparrow$ Peter FORGO $\dagger$ and Katalin E. KOVER $\ddagger$ \\ *University Medical School, Department of Biochemistry, Szigeti ut 12, 7623-Pecs, †Chinoin Pharmaceutical and Chemical Work Ltd., To u. 1-5, H-1045 Budapest, and \\ ‡Biogal Pharmaceutical Work, H-4042 Debrecen, Hungary
}

The oxidation of $\left[3-{ }^{13} \mathrm{C}\right]$ pyruvate and $\left[3-{ }^{13} \mathrm{C}\right]$ propionate was studied in vivo in infused rats. The infused $\left[3-{ }^{13} \mathrm{C}\right]$ pyruvate was quickly converted to $\left[3-{ }^{13} \mathrm{C}\right]$ lactate in the blood, and the [3${ }^{13} \mathrm{C}$ lactate formed was well metabolized in both normoxic and ischaemic hearts. Large differences $(200-600 \%)$ in the ${ }^{13} \mathrm{C}$ enrichment of alanine (C-3) and acetyl-CoA (C-2) compared with lactate (C-3) were found in both normoxic and ischaemic hearts, suggesting that the extracellular $\left[3-{ }^{13} \mathrm{C}\right]$ lactate preferentially entered a region of the cytoplasm which specifically transfers the labelled pyruvate (formed from $\left[3-{ }^{13} \mathrm{C}\right]$ lactate) to the mitochondria. The highly enriched mitochondrial pyruvate gave high enrichment in alanine and acetyl-CoA, which was detected by ${ }^{1} \mathrm{H}$ - and ${ }^{13} \mathrm{C}$-NMR spectroscopy. Ischaemia increased ${ }^{13} \mathrm{C}$ incorporation into the main cytoplasmic lactate pool and decreased
${ }^{13} \mathrm{C}$ incorporation into citric acid cycle intermediates, mainly decreasing the pyruvate anaplerosis. Isoprenaline-induced ischaemia of the heart caused only a slight decrease in pyruvate oxidation. In contrast to the decreased anaplerosis of pyruvate, the anaplerosis of propionate (and propionyl-carnitine) increased significantly in ischaemic hearts, which may contribute to the protective effect of propionyl-carnitine seen in ischaemia. In addition, we found that $\left[3-{ }^{13} \mathrm{C}\right]$ propionate preferentially labelled aspartate C-3 in rat heart, suggesting incomplete randomization of label in the succinyl-CoA-malate span of the citric acid cycle. These data show that proton observed ${ }^{13} \mathrm{C}$ edited spectroscopic methods, i.e. heteronuclear spin-echo and the one-dimensional heteronuclear multiple quantum coherence sequence, can be successfully used to study heart metabolism in vivo.

\section{INTRODUCTION}

Although fatty acids are the major fuel for the heart, there are several endogenous substrates which play an important role in heart metabolism [1-7]. Some features of heart metabolism are well established, but the relative utilization of all available substrates by the heart under various physiological conditions is quite subtle and complex [1-7]. Ischaemia influences substrate selection in perfused hearts, and the changes in substrate selection may have a significant effect on the recovery from post-ischaemic myocardium [4,7-9]. Therefore it is of great importance to understand the complexity of metabolism of normal and ischaemic hearts, so that we can develop new methods for improving recovery from post-ischaemic myocardium. Most of the studies on the heart have been carried out using the perfused model. These works have provided important information about the metabolism of the myocardium, but they have several limitations related to the in vitro nature of the experiments. In vivo studies can provide more reliable information about heart metabolism and the metabolic effects of ischaemia.

Previous publications have shown differences in the ${ }^{13} \mathrm{C}$ or ${ }^{14} \mathrm{C}$ enrichment of alanine and lactate in the perfused heart [10-12], despite the fact that both compounds were synthesized from pyruvate. These data were interpreted as evidence for the existence of different pyruvate pools in cardiomyocytes [10-12]. In the present work we studied the compartmentalization of lactate and pyruvate in normal and ischaemic hearts of living animals and investigated the effect of isoprenaline-induced ischaemia on heart pyruvate and propionate metabolism. The ${ }^{13} \mathrm{C}$ enrichment in metabolites was also determined by proton observed ${ }^{13} \mathrm{C}$ edited (POCE) spectroscopy.

\section{MATERIALS AND METHODS}

\section{Materials}

$\left[3-{ }^{13} \mathrm{C}\right]$ Pyruvate (sodium salt) and $\left[{ }^{[-13} \mathrm{C}\right]$ propionate (sodium salt) were obtained from ISOTEC, Miamisburg, OH, U.S.A. All other chemicals were of the highest purity commercially available.

\section{General methods}

Male Wistar rats weighing 200-250 g were used for infusion studies. The animals were anaesthetized with Ketalane and infused with the ${ }^{13} \mathrm{C}$-labelled substrates through the jugular vein. The infusion solution contained physiological salt and either [3$\left.{ }^{13} \mathrm{C}\right]$ pyruvate or $\left[3-{ }^{13} \mathrm{C}\right]$ propionate. The infusion rate was $0.15 \mathrm{ml} / \mathrm{min}$, and the infusion solution contained $26 \mathrm{mg} / \mathrm{ml}{ }^{13} \mathrm{C}$ labelled substrate. After the indicated infusion times the hearts were freeze-clamped and removed. The frozen heart tissue was extracted with $3 \mathrm{ml}$ of $7 \%$ perchloric acid, neutralized with $5 \mathrm{M}$ $\mathrm{KOH}$, freeze-dried and redissolved in ${ }^{2} \mathrm{H}_{2} \mathrm{O}$ for NMR spectroscopy.

Myocardial ischaemia was induced by injecting $5 \mathrm{mg} / \mathrm{kg}$ isoprenaline daily for five consecutive days preceding the infusion with ${ }^{13} \mathrm{C}$-labelled substrates. Following this treatment, necrosis and hypoxia were evaluated as described [13,14]. The $5 \mathrm{mg} / \mathrm{kg}$ dose of isoprenaline was found to be optimal because it was large enough to cause significant necrosis and impaired heart function, but mortality was low [14].

\section{NMR mothods}

All NMR experiments were carried out on a BRUKER AC400/P spectrometer equipped with an ASPECT-3000 computer

Abbreviations used: HSQC, heteronuclear single quantum coherence; HMQC, heteronuclear multiple quantum coherence; POCE spectroscopy, proton observed ${ }^{13} \mathrm{C}$ edited spectroscopy; DEPT, distortionless enhancement by polarization transfer; GARP, globally optimized alternating-phase rectangular pulses; $1 \mathrm{D}$, one-dimensional.

$\S$ To whom correspondence should be addressed. 
and a $5 \mathrm{~mm}$ inverse probehead. The samples were dissolved in $0.5 \mathrm{ml}$ of ${ }^{2} \mathrm{H}_{2} \mathrm{O}$, and $10 \mathrm{ml}$ of a solution containing $0.3 \mathrm{M}$ dioxane and 0.015 M EDTA was added. Dioxane was used as chemicalshift reference (67.4 and 3.749 p.p.m. for ${ }^{13} \mathrm{C}$ - and ${ }^{1} \mathrm{H}-\mathrm{NMR}$ spectra respectively). Proton-decoupled carbon spectra were recorded with a $9.5 \mathrm{~ms}$ carbon excitation pulse $\left(90^{\circ}\right.$ pulse was $11.8 \mathrm{~ms}$ ), and $8 \mathrm{~s}$ repetition delay. Four different methods, namely heteronuclear spin-echo, inverse distortionless enhancement by polarization transfer (DEPT), one-dimensional (1D) nonselective heteronuclear single quantum coherence (HSQC) and heteronuclear multiple quantum coherence (HMQC), were used to obtain POCE spectra.

\section{D proton-detected experiment based on heteronuclear spin-echo}

The conventional spin-echo was used for selectively observing protons attached to ${ }^{12} \mathrm{C}$ or ${ }^{13} \mathrm{C}$ [15]. The pulse sequence begins with a proton $90^{\circ}$ pulse followed by a fixed delay, $J_{\mathrm{CH}}$, optimized for $150 \mathrm{~Hz}$. During this delay heteronuclear coupling evolves, generating antiphase coherence from protons bound to ${ }^{13} \mathrm{C}$. The proton $180^{\circ}$ pulse applied in the middle of the spin-echo period refocuses the chemical shift evolution, whereas the two carbon $90^{\circ}$ pulses act together giving a $180^{\circ}$ or a $0^{\circ}$ pulse in successive transients. As a consequence, the antiphase coherence continuously dephases or rephases during the second half of the echo period, giving rise to a $180^{\circ}$ phase difference of ${ }^{1} \mathrm{H}-\left({ }^{13} \mathrm{C}\right)$ signals acquired in subsequent experiments. Therefore, when protons bound to ${ }^{13} \mathrm{C}$ are to be selectively observed, the signals acquired in alternate experiments should be subtracted. In contrast, by addition of signals, the ${ }^{1} \mathrm{H}-\left({ }^{12} \mathrm{C}\right)$ magnetization, which is indifferent to the carbon pulses, is co-added and the undesired ${ }^{1} \mathrm{H}$ $\left({ }^{13} \mathrm{C}\right)$ magnetization is suppressed. To check the efficiency of signal selection, i.e. the quality of ${ }^{1} \mathrm{H}-\left({ }^{12} \mathrm{C}\right) /{ }^{1} \mathrm{H}-\left({ }^{13} \mathrm{C}\right)$ editing, the experiment was initially carried out without carbon decoupling, allowing the separation of ${ }^{1} \mathrm{H}-\left({ }^{13} \mathrm{C}\right)$ resonances due to the large one-bond heteronuclear coupling. Good suppression of unwanted signals was verified, then ${ }^{13} \mathrm{C}$ globally optimized alternating-phase rectangular pulses (GARP) decoupling was applied during the acquisition, generating the $68 \mathrm{~ms} 90^{\circ}{ }^{13} \mathrm{C}$ pulses through a BFX-5 linear amplifier. The acquisition time was reduced to $0.4 \mathrm{~s}$ to avoid heating the sample. The relaxation delay was $2.0 \mathrm{~s}$. Typically, 800 transients were accumulated and $0.7 \mathrm{~Hz}$ exponential multiplication was applied prior to Fourier transformation.

\section{D HSQC experiment}

We used the basic HSQC experiment proposed by Bodenhausen and Ruben [16] without refocusing to obtain the 1D satellite spectrum. The relaxation delay and pulse widths were the same as in the previous method. The total length of the INEPT sequence in the experiment was set to $3.3 \mathrm{~ms}$. The desired magnetization component, ${ }^{1} \mathrm{H}-\left({ }^{12} \mathrm{C}\right)$ or ${ }^{1} \mathrm{H}-\left({ }^{13} \mathrm{C}\right)$, was selected by the phase shifting of the receiver and the first polarization transfer proton pulse.

\section{D HMQC experiment}

The standard HMQC sequence [17] was used to obtain the POCE spectrum. The desired magnetization component, ${ }^{1} \mathrm{H}-$ $\left({ }^{12} \mathrm{C}\right)$ or ${ }^{1} \mathrm{H}-\left({ }^{13} \mathrm{C}\right)$, was selected by the modifying the receiver phase, i.e. phase shifts corresponding to HMQC selection were omitted.

\section{0 inverse DEPT experiment [18]}

We used a modified BRUKER library program to obtain a multiplicity edited $1 \mathrm{D}$ proton spectrum. The delays $\left({ }_{1} J\right)$ between the pulses were set to $3.3 \mathrm{~ms}(J=150 \mathrm{~Hz})$. A proton polarization transfer pulse of $45^{\circ}$ was applied to obtain a spectrum with all multiplets having the same phase. During the relaxation delay $(2 \mathrm{~s})$, broadband proton presaturation was applied to enhance the carbon polarization via a heteronuclear NOE effect.

\section{Evaluation of ${ }^{13} \mathrm{C}$ enrichment of C-2 of acetyl-CoA}

It is possible to calculate the ${ }^{13} \mathrm{C}$ enrichment of the acetyl-CoA pool by isotopomer analysis of glutamate [19], since the C-2 of acetyl-CoA becomes the C- 4 of glutamate in the citric acid cycle. Glutamate $\mathrm{C}-3$ is a singlet if unlabelled acetyl-CoA is attached to $\left[2-{ }^{13} \mathrm{C}\right]$ oxaloacetate, while it is a doublet (C-3-C-4) if [2$\left.{ }^{13} \mathrm{C}\right]$ acetyl-CoA and $\left[2-{ }^{13} \mathrm{C}\right]$ oxaloacetate are converted into glutamate. Thus the ratio of the integrated intensity of the glutamate C-3-C-4 doublet to the intensity of the glutamate C-3 singlet indicates the $\left[2-{ }^{13} \mathrm{C}\right]$ acetyl-CoA $/\left[2-{ }^{12} \mathrm{C}\right]$ acetyl-CoA ratio, i.e. the ${ }^{13} \mathrm{C}$ enrichment of the acetyl-CoA pool. However, the intensity of the glutamate C-3-C-4 doublet cannot be determined directly, because the measured intensity of the glutamate C-3 doublet is the sum of the glutamate C-2-C-3 and C-3-C-4 doublets. If we subtract the intensity of glutamate $\mathrm{C}-2-\mathrm{C}-3$ from the glutamate C-3 doublet intensity then we obtain the area of the glutamate C3-C-4 doublet. The area of glutamate C-2-C-3 can be determined from the glutamate $\mathrm{C}-2$ spectral region, because the NOE is the same for glutamate C-2 and C-3 under our experimental conditions.

\section{RESULTS}

\section{Determination of ${ }^{13} \mathrm{C}$ enrichments in different metabolites by ${ }^{1} \mathrm{H}$ - NMR spectroscopy}

Pyruvate metabolism was studied in the hearts of $\left[3-{ }^{13} \mathrm{C}\right]$ pyruvateinfused Wistar rats by ${ }^{13} \mathrm{C}$ - and ${ }^{1} \mathrm{H}$-NMR spectroscopy. The ${ }^{13} \mathrm{C}$ enrichment of alanine C-3 and lactate C-3 can be determined from the intensity ratio of the lactate and the alanine methyl

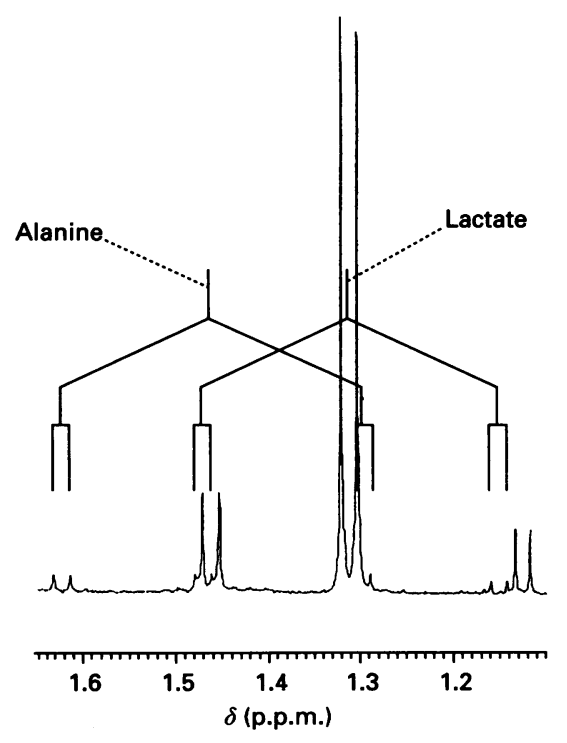

Figure 1 Part of the ${ }^{1} \mathrm{H}-\mathrm{NMR}$ spectrum of a heart extract from a rat injected with [3-13C]pyruvate 

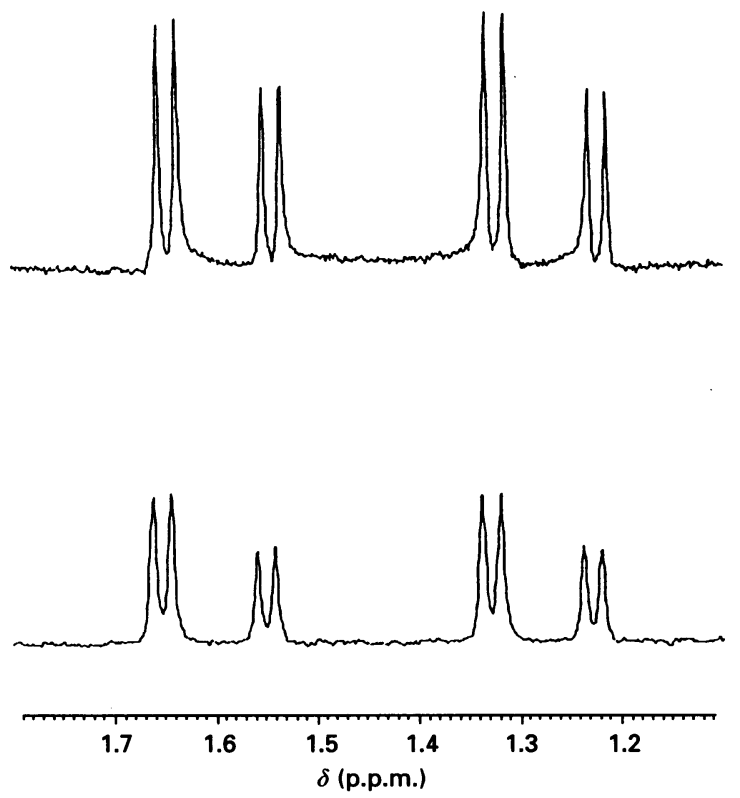

Figure 2 Parts of the heteronuclear spin-echo spectra of a heart extract from a rat injected with [3- $\left.{ }^{13} \mathrm{C}\right]$ pyruvate

Upper spectrum, obtained with the original pulse sequence; lower spectrum, obtained using a purging pulse sequence.

doublets to their ${ }^{13} \mathrm{C}$ satellite signals (Figure 1). However, in general the low intensity of the satellite peaks can cause problems, because overlapping of these signals with other peaks may hinder the use of this procedure even in those cases when the ${ }^{12} \mathrm{C}-\mathrm{H}$ signals of the ${ }^{1} \mathrm{H}-\mathrm{NMR}$ spectrum are clearly resolved.

To avoid this problem, we tested the use of POCE spectroscopy to obtain the enrichment factors in heart extracts. POCE spectra contain only the signals of those protons which are connected to ${ }^{13} \mathrm{C}$ atoms. To obtain the ${ }^{13} \mathrm{C}$ enrichment factors $(f)$, we added [1${ }^{13} \mathrm{C}$ glucose with known ${ }^{13} \mathrm{C}$ enrichment to the heart extract solutions. From the normal ${ }^{1} \mathrm{H}-\mathrm{NMR}$ spectrum we measured the intensity ratio of the ${ }^{12} \mathrm{C}$-bound protons of the carbons in question (lactate $\mathrm{C}-3$ and alanine $\mathrm{C}-3$ ) to the ${ }^{12} \mathrm{C}-\mathrm{H}$ signal of glucose $1-\mathrm{H}_{\mathrm{a}}\left(R_{12}\right)$. From the POCE spectrum, we measured the intensity ratio of the ${ }^{13} \mathrm{C}$-bound protons of the same carbons to the $1{ }^{13} \mathrm{C}-\mathrm{H}_{\mathrm{a}}$ signal of glucose $\left(R_{13}\right)$. The measured intensity ratios can be expressed in terms of the enrichment factors (eqns. 1 and 2), where $c$ is the concentration, and $u$ labels the compound with an unknown and $k$ with a known enrichment factor.

$R_{13}=\left(c_{u}^{*} f_{u}\right) /\left(c_{k}^{*} f_{k}\right)$

$R_{12}=\left[c_{u}^{*}\left(1-f_{u}\right)\right] /\left[c_{k}^{*}\left(1-f_{k}\right)\right]$

The unknown enrichment factor can be calculated from these two equations:

$f_{u}=\left(R_{13}{ }^{*} f_{k}\right) /\left[R_{12}+\left(R_{13}{ }^{*} f_{k}\right)-\left(R_{12}{ }^{*} f_{k}\right)\right]$

Several types of experiments can be used to obtain POCE spectra. We tested four methods with the heart extract samples: heteronuclear spin-echo [15], inverse DEPT [18], 1D HSQC [16] and 1D HMQC [17]. The methyl region of the heteronuclear spin-echo spectrum of a normal heart extract treated with [3${ }^{13} \mathrm{C}$ ]pyruvate for $15 \mathrm{~min}$ obtained by the microprogram of the Bruker library can be seen on Figure 2 (upper trace). The signals show some phase distortions which can result in errors of the integrals. To improve the quality of the spectra, we inserted a
Table 1 Incorporation of ${ }^{13} \mathrm{C}$ lsotope Into C-3 of alanine and lactate from [3-13 C]pyruvate obtained by different methods

\begin{tabular}{lll}
\hline & \multicolumn{2}{l}{ Incorporation (\%) } \\
\cline { 2 - 3 } Method & Alanine C-3 & Lactate C-3 \\
\hline & & \\
\hline Integration of satellite signals & 41 & 27 \\
Inverse DEPT & 29 & 18 \\
DD HSQC & 27 & 19 \\
D HSQC using reference compound & 28 & 15 \\
1D HMQC & 34 & 20 \\
1D HMQC using reference compound & 40 & 28 \\
Heteronuclear spin-echo & 41 & 20 \\
Heteronuclear spin-echo using reference compound & 39 & 26 \\
\end{tabular}

purging pulse prior to acquisition and this resulted in pure phase signals (Figure 2, lower trace). To enhance the signal-to-noise ratio, ${ }^{13} \mathrm{C}$ GARP decoupling was employed during detection. The ${ }^{13} \mathrm{C}$ enrichment factors of alanine and lactate methyl groups calculated from this spectrum, together with data determined from the direct integration of the satellite peaks, are listed in Table 1 . The ${ }^{13} \mathrm{C}$ incorporation ratios of the same sample were also determined by inverse DEPT, 1D HSQC, and 1D HMQC experiments, and the values obtained are summarized in Table 1. The data listed in Table 1 show that the best match of the directly determined ratios was achieved by the heteronuclear spin-echo and the 1D HMQC methods. A significant deviation from these values can be seen in the enrichment factors obtained from the inverse DEPT and 1D HSQC experiments. These errors are probably due to the polarization transfer steps of these sequences, when coupling constants differing from the optimal value can result in intensity distortions. The 1D HMQC and the heteronuclear spin-echo methods provided more accurate enhancement factors because both sequences use fewer pulses and thereby are less sensitive to pulse imperfections.

The heteronuclear spin-echo, the 1D HSQC and the 1D HMQC methods can be used to obtain the incorporation ratios without a reference compound. By modification of the phase cycling as described above the methods can be used to record ${ }^{1} \mathrm{H}$ $\left({ }^{12} \mathrm{C}\right)$ or ${ }^{1} \mathrm{H}-\left({ }^{13} \mathrm{C}\right)$ edited spectra separately. The intensity ratio of the relevant signals in the two spectra provides the incorporation ratio. The values determined this way are also listed in Table 1. A comparison of these values with the directly determined enrichment factors leads to the conclusion that the use of a reference compound increases the accuracy in all cases.

\section{Pyruvate metabolism in normal heart}

The infused $\left[3-{ }^{13} \mathrm{C}\right]$ pyruvate was quickly converted to [3${ }^{13} \mathrm{C}$ lactate in the blood of Wistar rats under our experimental conditions. Although we continuously infused rats with [3${ }^{13} \mathrm{Clpyruvate}$, at the end of the 5,10 or $15 \mathrm{~min}$ of infusion only $\left[3-{ }^{13} \mathrm{C}\right]$ lactate (i.e. no $\left[3-{ }^{13} \mathrm{C}\right]$ pyruvate) was detected in the blood by ${ }^{13} \mathrm{C}$ - or ${ }^{1} \mathrm{H}$-NMR spectroscopy (results not shown). Therefore we assume that the ${ }^{13} \mathrm{C}$-labelled substrate entering the heart from the blood is mainly $\left[3-{ }^{13} \mathrm{C}\right]$ lactate. The ${ }^{13} \mathrm{C}$ enrichment of the lactate pool in the blood varied between 20 and $30 \%$ in different animals, as determined by ${ }^{1} \mathrm{H}-\mathrm{NMR}$ spectroscopy.

After 5,10 or $15 \mathrm{~min}$ of infusion with $\left[3-{ }^{13} \mathrm{C}\right]$ pyruvate, the ${ }^{13} \mathrm{C}$ enrichment of lactate C-3 and alanine C-3 was determined in normoxic rat hearts (Table 2). These data show that the ${ }^{13} \mathrm{C}$ enrichment of alanine C-3 was about 3-6 times higher than that of intracellular lactate C-3 (Table 2; 10 and 15 min infusion). 
Table 2 Pyruvate metabolism in hearts of $\left[3-{ }^{13} \mathrm{C}\right]$ pyruvate-infused rats

Experimental conditions are described in the Materials and methods section. Values in parentheses are signal intensities, relative to the methyl signal of creatine. n.d., not done.

\begin{tabular}{|c|c|c|c|c|}
\hline \multirow{2}{*}{$\begin{array}{l}\text { Infusion } \\
\text { time } \\
\text { (min) }\end{array}$} & \multirow[b]{2}{*}{$n$} & \multicolumn{3}{|l|}{${ }^{13} \mathrm{C}$ enrichment (\%) } \\
\hline & & Alanine C-3 & Lactate C-3 & $\begin{array}{l}\text { Acetyl-CoA } \\
\text { C-2 }\end{array}$ \\
\hline \multicolumn{5}{|c|}{ Normal hearts } \\
\hline $\begin{array}{r}5 \\
10 \\
15\end{array}$ & $\begin{array}{l}3 \\
3 \\
4\end{array}$ & $\begin{array}{c}9.1 \pm 5.5(0.09 \pm 0.014) \\
19.6 \pm 2.3(0.10 \pm 0.01) \\
21.8 \pm 10.0(0.10 \pm 0.02)\end{array}$ & $\begin{array}{l}3.7 \pm 0.5(0.17 \pm 0.06) \\
6.1 \pm 4.9(0.47 \pm 0.30) \\
5.4 \pm 2.0(0.30 \pm 0.14)\end{array}$ & $\begin{array}{l}\text { n.d. } \\
17.0 \pm 2.4 \\
23.3 \pm 3.6\end{array}$ \\
\hline \multicolumn{5}{|c|}{ Ischaemic heart } \\
\hline 15 & 2 & $22.5 \pm 0.5(0.16 \pm 0.10)$ & $6.2 \pm 1.7(0.88 \pm 0.29)$ & $18.0 \pm 2.1$ \\
\hline
\end{tabular}

Interestingly, the ${ }^{13} \mathrm{C}$ enrichment of the blood lactate (20-30\%) is similar to the enrichment of intracellular alanine pool (Table 2), while the ${ }^{13} \mathrm{C}$ enrichment of intracellular lactate was much lower (Table 2).

The ${ }^{13} \mathrm{C}$ enrichment of the mitochondrial acetyl-CoA pool was also determined from the glutamate isotopomers by ${ }^{13} \mathrm{C}-\mathrm{NMR}$ spectroscopy as described in the Materials and methods section, and we found that the ${ }^{13} \mathrm{C}$ enrichment of acetyl-CoA C-2 is similar to the ${ }^{13} \mathrm{C}$ enrichment of the alanine C-3 pool (Table 2). Since $\left[2-{ }^{13} \mathrm{C}\right]$ acetyl-CoA is derived from the mitochondrial pyruvate pool, the similar ${ }^{13} \mathrm{C}$ enrichments of acetyl-CoA and alanine suggests that they were formed from the same, or equilibrating, pyruvate pool. On the other hand, the low ${ }^{13} \mathrm{C}$ enrichment of the lactate pool suggests that the intracellular lactate pool is mainly derived from unlabelled glucose in the cytoplasm, and that this glycolytic pyruvate or lactate pool does not equilibrate with the mitochondrial pyruvate pool. These observations are in accordance with other data indicating the existence of different pyruvate pools in cardiomyocytes [10-12].
The ${ }^{13} \mathrm{C}-\mathrm{NMR}$ spectra of the heart extracts showed significant ${ }^{13} \mathrm{C}$ incorporation into glutamate C-4, C-3 and C-2 (Figure 3). Surprisingly, in several experiments the ${ }^{13} \mathrm{C}$ labelling was higher in glutamate C-2 and C-3 than in glutamate C-4 [20], indicating active anaplerotic metabolism of pyruvate in the normoxic heart.

\section{Effect of Ischaemia on heart pyruvate metabolism}

Studying pyruvate metabolism in ischaemic hearts, we found that the quantity of lactate was significantly higher in ischaemic hearts $(0.88 \pm 0.29)$ than in normal hearts $(0.30 \pm 0.14)$ (values are intensities relative to the methyl signal of creatine). The ${ }^{13} \mathrm{C}$ fractional enrichment of lactate in the ischaemic heart was close to that of normal hearts (Table 2), and so the calculated quantity of ${ }^{13} \mathrm{C}$ label in the intracellular lactate pool was 3.3 times higher in ischaemic than in normoxic hearts. This is also supported by the ${ }^{13} \mathrm{C}$-NMR data showing a significantly higher lactate $\mathrm{C}-3$ peak (normalized for taurine) in the ischaemic hearts than in the normoxic hearts (Figure 3). Furthermore, the lactate C-3/alanine C-3 ratio was almost twice as high in the ischaemic hearts compared with the normoxic hearts (Figure 3), indicating a preference for the pyruvate/lactate over the pyruvate/alanine pathway in ischaemic hearts.

Measurement of ${ }^{13} \mathrm{C}$ incorporation into glutamate showed that the ischaemic hearts incorporated $46 \%$ less ${ }^{13} \mathrm{C}$ into glutamate $\mathrm{C}-2$ and $\mathrm{C}-3$ than the normal hearts, and there was also a smaller decrease in the ${ }^{13} \mathrm{C}$ enrichment of glutamate $\mathrm{C}-4$ (these values are normalized for taurine peaks). A possible explanation for the lower ${ }^{13} \mathrm{C}$ incorporation into glutamate in ischaemic hearts is the slightly lower ${ }^{13} \mathrm{C}$ enrichment in the acetyl-CoA pool (Table 2) and the lower anaplerotic rate in ischaemic hearts.

\section{Propionate metabolism in normoxic and ischaemic hearts}

Propionate is an anaplerotic substrate which enters the citric acid cycle at succinyl-CoA (Figure 4). $\left[3-{ }^{13} \mathrm{C}\right]$ Propionate was well
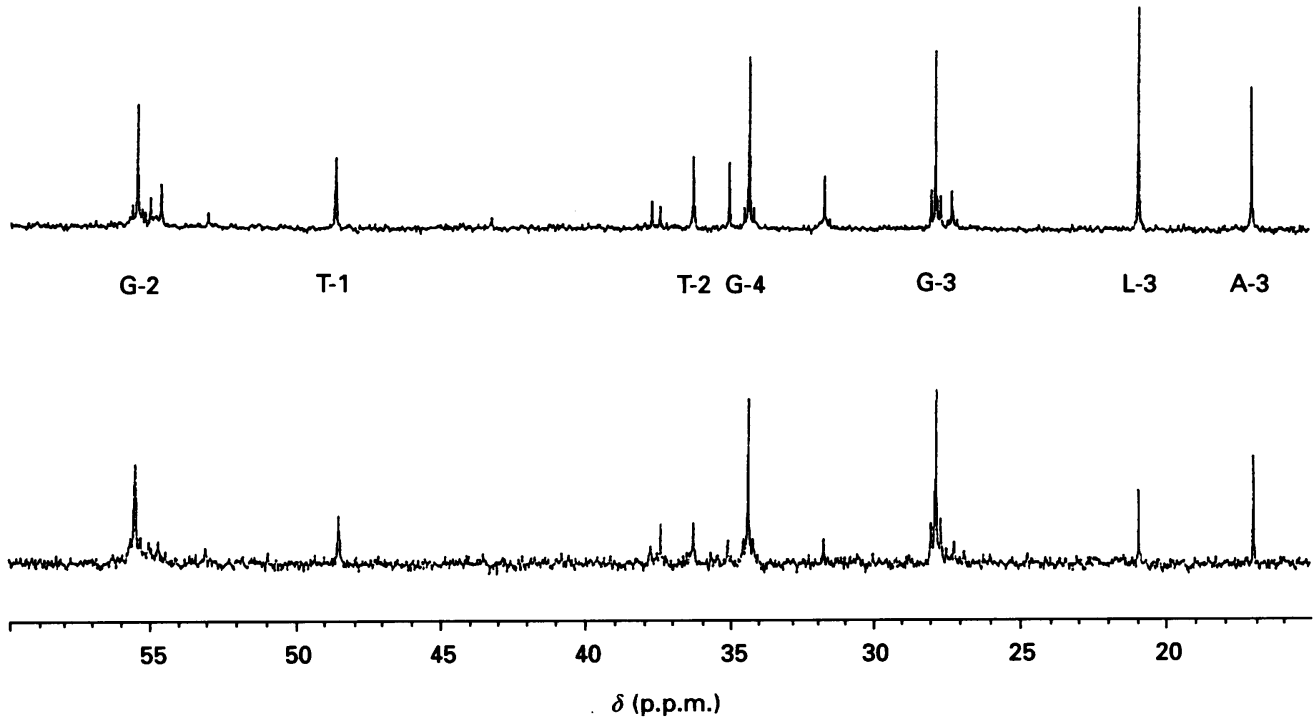

Figure $3{ }^{13} \mathrm{C}$-NMR spectra of heart extracts dertved from [3-13 C]pyruvate-infused rats (15 min infusion) 


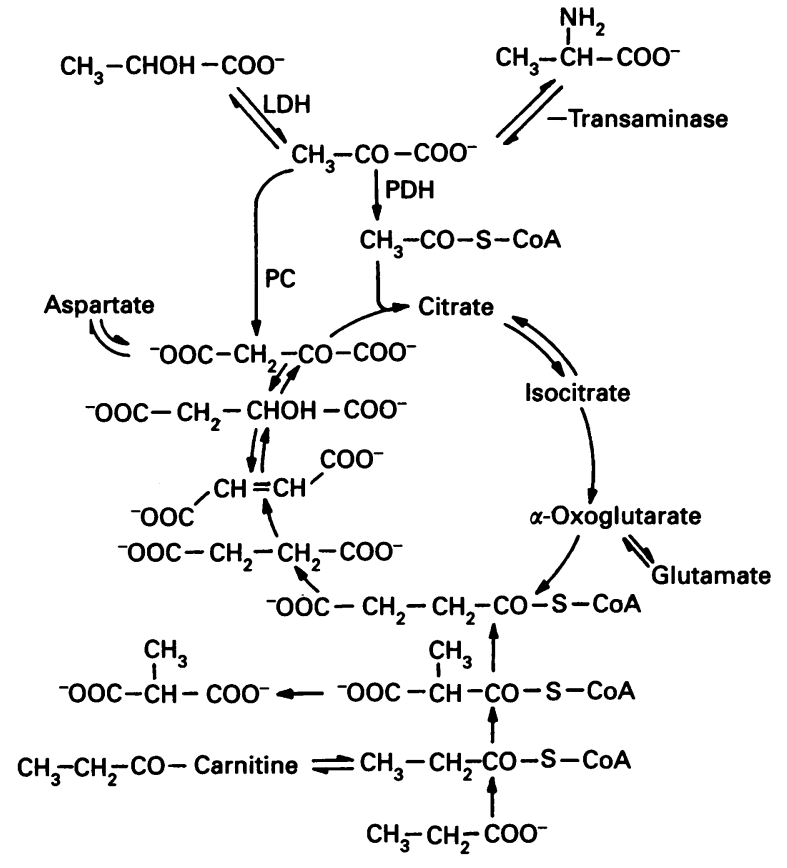

Figure 4 General scheme for pyruvate and propionate metabolism in the rat heart

LDH, lactate dehydrogenase; PDH, pyruvate dehydrogenase complex; PC, pyruvate carboxylase.

oxidized in both normoxic and ischaemic hearts, and intermediates of propionate metabolism, such as propionyl-carnitine and methylmalonate, were detected by ${ }^{13} \mathrm{C}-\mathrm{NMR}$ (Figure 5). Significant amounts of ${ }^{13} \mathrm{C}$-label were incorporated into aspartate C-2 and C-3 and malate C-2 and C-3 in both normoxic and ischaemic hearts, but we could only detect very limited ${ }^{13} \mathrm{C}$ labelling in glutamate C-2, C-3 and C-4 (Figure 5), which is in accordance with previous data from perfused hearts [20].

Interestingly, the oxidation of $\left[3-{ }^{13} \mathrm{C}\right]$ propionate did not give equal labelling in aspartate in the infused animals; the aspartate $\mathrm{C}-3 / \mathrm{C}-2$ ratio was $1.5 \pm 0.1$ in normal hearts and $1.2 \pm 0.1$ in ischaemic hearts, in spite of the fact that non-selective heteronuclear NOEs for aspartate C-2 and C-3 are approximately the same under our experimental conditions (results not shown). This phenomenon was also seen in perfused heart experiments, where the oxidation of $\left[3-{ }^{13} \mathrm{C}\right]$ propionate gave higher labelling in aspartate C-3 than in C-2 [20]. Our data (Figure 5) and previous data [19] indicate incomplete scrambling in the succinyl$\mathrm{CoA} /$ malate span of the citric acid cycle under the conditions of propionate oxidation.

The ${ }^{13} \mathrm{C}$ content of the malate pool was higher in the ischaemic hearts than in normoxic hearts, and the ${ }^{13} \mathrm{C}$ content of aspartate was approximately the same in both ischaemic and normoxic hearts (standardized for taurine), in spite of the fact that the ${ }^{13} \mathrm{C}$ contents of propionate and its metabolites (propionate, propionyl-carnitine, methylmalonate) are lower in the ischaemic hearts than in the normal hearts (Figure 5). The aspartate $\mathrm{C}$ 3/propionyl-carnitine C-3 ratio was increased more than 3-fold in the ischaemic hearts compared with the normoxic hearts, and there was an approx. 6-fold increase in the malate C-3/propionylcarnitine $\mathrm{C}-3$ ratio in ischaemic hearts over normoxic hearts. Similar changes were found when we used propionate $\mathrm{C}-3$ as reference instead of propionyl-carnitine C-3, indicating that ischaemic hearts convert the intracellular propionate and propionyl-carnitine to citric acid cycle intermediates much more effectively than do normal hearts.

\section{DISCUSSION}

The presented data show that the ${ }^{13} \mathrm{C}$ atoms of $\left[3-{ }^{13} \mathrm{C}\right]$ pyruvate are incorporated mainly into glutamate, lactate and alanine both

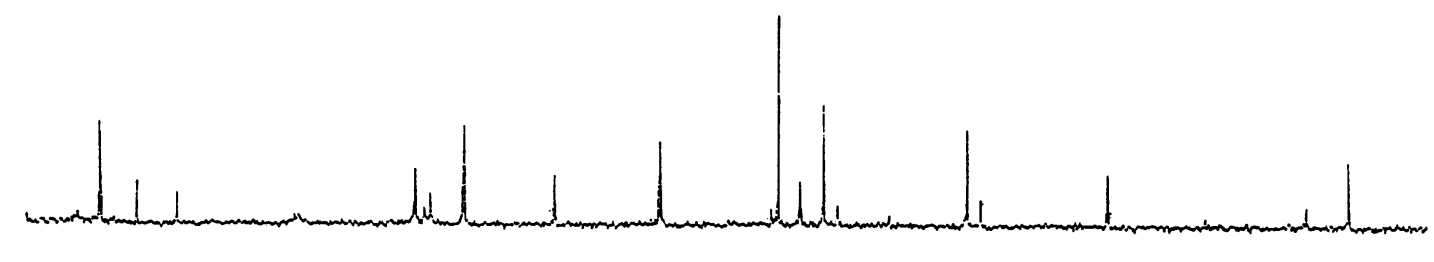

$\begin{array}{llllllll}\text { M-2 } & \text { As-2 } & \text { T-1 } & \text { M-3 } & \text { As-3 } & \text { MM } & \text { P-3 } & \text { C-3 }\end{array}$

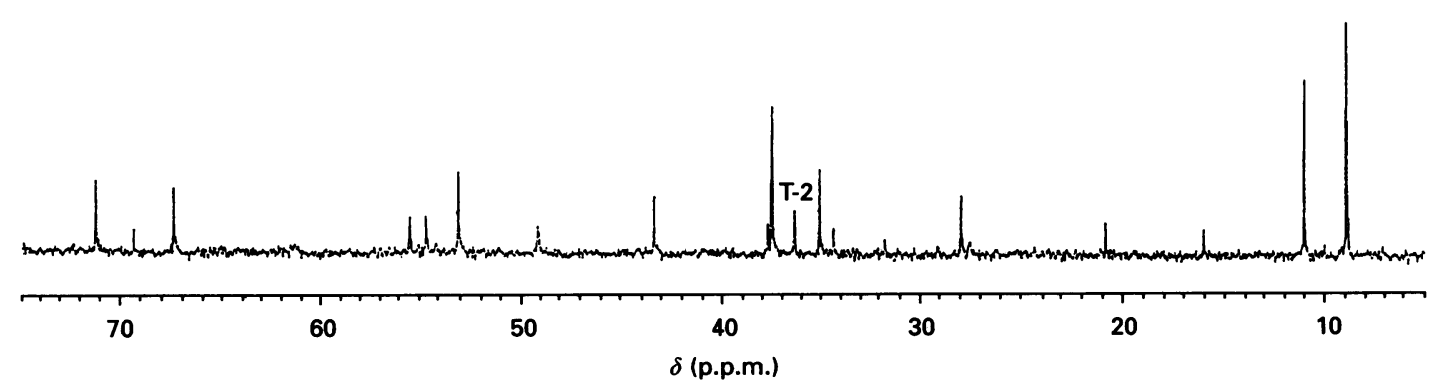

Figure $5{ }^{13} \mathrm{C}$-NMR spectra of heart extracts from rats infused with [3--33]proplonate

Experimental conditions are described in the Materials and methods section. Lower spectrum, normoxic heart; upper spectrum, ischaemic heart. T, taurine; As, aspartate; M, malate; MM, methylmalonate; P, propionate; C, propionyl-carnitine. 
in normoxic and in ischaemic hearts. Interestingly, significantly higher ${ }^{13} \mathrm{C}$ enrichment was found in alanine $\mathrm{C}-3$ than in lactate C-3 (intracellular) (Table 2), in spite of the fact that the infused $\left[3-{ }^{13} \mathrm{C}\right]$ pyruvate was quickly converted to $\left[3-{ }^{13} \mathrm{C}\right]$ lactate in the blood and this highly enriched lactate was taken up from the blood. We also found that the ${ }^{13} \mathrm{C}$ enrichment in acetyl-CoA was almost equal to the ${ }^{13} \mathrm{C}$ enrichment of alanine, suggesting that alanine and acetyl-CoA are derived from the same pyruvate pool. Necessarily, the acetyl-CoA is derived from the mitochondrial pyruvate pool; therefore we have to assume that alanine is either produced in the mitochondria or derived from a cytoplasmic pyruvate pool which equilibrates with the mitochondrial pyruvate pool.

We found that the ${ }^{13} \mathrm{C}$ enrichment in lactate did not change with time, suggesting that the equilibrium was reached in less than $5 \mathrm{~min}$. In contrast to the lactate ${ }^{13} \mathrm{C}$ enrichment, the ${ }^{13} \mathrm{C}$ enrichment of the alanine pool increased with time (Table 2), indicating that the ${ }^{13} \mathrm{C}$ enrichment in alanine represents a true metabolic flux from pyruvate to alanine, as suggested by Wolfe et al. [11].

Other laboratories have suggested the existence of multiple pyruvate pools in cardiomyocytes using proton NMR spectroscopy [12] and ${ }^{14} \mathrm{C}$ specific activity determination studies in experiments with perfused rat hearts [10]. In these perfused rat heart studies there was less than a $100 \%$ difference in the ${ }^{13} \mathrm{C}$ enrichments of alanine C-3 and lactate C-3, while in our in vivo studies differences as great as $600 \%$ were found in the ${ }^{13} \mathrm{C}$ enrichment of alanine C-3 compared with lactate C-3 (Table 2). The difference between perfused heart studies and our infusion study may be the consequence of the different experimental conditions, since perfusion takes place in an artificial buffer. There may also be a trauma during the removal of the heart for perfusion, or the retrograde perfusion might cause damage which results in the partial mixing of different intracellular pyruvate pools.

The large difference in the ${ }^{13} \mathrm{C}$ enrichments of lactate $\mathrm{C}-3$ and alanine $\mathrm{C}-3$ are even more surprising in this work than in the perfusion studies, because the infused animals quickly convert the $\left[3-{ }^{13} \mathrm{C}\right]$ pyruvate to $\left[3-{ }^{13} \mathrm{C}\right]$ lactate in the blood. Therefore these data show that the exracellular lactate is preferentially taken up by a portion of cytoplasm which converts the lactate to pyruvate and transfers it to the mitochondrial reticular network. The lactate in this specific region of the cytoplasm does not mix with the main cytoplasmic lactate pool, which is probably derived from unlabelled glucose. There is no information about the molecular mechanism of this specific mitochondrial lactate/ pyruvate uptake, but we have to assume that a fraction of the cytoplasm associated with the mitochondrial reticular network is specialized for converting the lactate to pyruvate, with the pyruvate being channelled to the mitochondria, while another cytoplasmic region is specialized to export the lactate formed from unlabelled glucose. That is, we have to assume an oxidative and an anaerobic region within one cardiomyocyte, with well separated substrate pools. As for the morphological background to this hypothesis, we know that the glycolytic enzymes are associated with the myofibres, while the mitochondria are densely packed between these fibres. Therefore we can assume that regions in the plasma membrane connected with either the myofibres or the mitochondrial network are involved in either the export or the import of lactate and pyruvate. Our results indicate that lactate and pyruvate are not well transported across the myofibre-mitochondria interface.

There is an alternative explanation for these observations if we assume that these two functions are performed by different cells. That is, there are cells which gain energy mainly from glycolysis and produce lactate, while other cells obtain energy from the oxidation of substrates (such as lactate) and produce alanine. Although there is no direct morphological evidence for such heterogeneity of the cell population, there are data suggesting heterogeneity of heart contractile function [21,22], oxygen consumption $[23,24]$ and in the distribution of glycolytic enzymes [25]. These data may support the idea that different regions in the heart perform preferential oxidative metabolism or preferentially use glycolysis as energy source, and these heterogeneities can cause different labelling patterns in lactate and alanine.

The most common heart diseases are associated with ischaemia, and therefore it is important to study how ischaemia affects pyruvate/lactate compartmentalization. The ischaemia caused by isoprenaline injections was associated with serious morphological changes in cardiomyocytes [14], but the specific ${ }^{13} \mathrm{C}$ enrichment in the lactate pool of ischaemic hearts did not change significantly. The lactate pool size increased 3 -fold in ischaemic hearts, which means that approx. 3 times more ${ }^{13} \mathrm{C}$ label was present in lactate in ischaemic hearts than in normal hearts. That is, ischaemic damage facilitates the uptake of highly enriched extracellular lactate by cardiomyocytes.

The high ${ }^{13} \mathrm{C}$ enrichment in glutamate $\mathrm{C}-2$ and $\mathrm{C}-3$ in normoxic hearts indicates that a significant portion of pyruvate entered the citric acid cycle in an anaplerotic pathway (through pyruvate carboxylase). The fact that ${ }^{13} \mathrm{C}$ incorporation into glutamate $\mathrm{C}$ 2 and C-3 decreased (46\%) in ischaemia indicates that the rate of this anaplerotic (pyruvate-oxaloacetate) pathway decreased significantly in ischaemic hearts.

It has been suggested that propionyl-carnitine exerts a beneficial effect on the ischaemic heart [26-28], but the mechanism of action is not well understood. Since propionyl-carnitine is metabolized like propionate, it would be interesting to investigate how propionate influences the metabolism of the ischaemic heart. It is well known that propionate is converted to succinylCoA in a vitamin $B_{12}$-dependent pathway [29] (Figure 4), and so propionate can refill the citric acid cycle intermediates via a completely different pathway to pyruvate. On infusing rats with $\left[3-{ }^{13} \mathrm{C}\right]$ propionate, we found that the propionate was converted mainly to aspartate and malate in both normal and ischaemic hearts (Figure 5), but it is very clear that the ischaemic hearts converted the intracellular $\left[3-{ }^{13} \mathrm{C}\right]$ propionate (or propionylcarnitine) to aspartate and malate much more effectively than the normal hearts. It seems that the enhanced anaplerosis from propionate compensates for the reduced anaplerosis from endogenous pyruvate in ischaemia. That is, the very active refilling of citric acid cycle intermediates from propionate can contribute to the beneficial effect of propionyl-carnitine in ischaemic hearts.

In addition, we found that $\left[3^{13} \mathrm{C}\right]$ propionate is preferentially converted to $\left[3-{ }^{13} \mathrm{C}\right]$ aspartate (aspartate $\mathrm{C}-3 / \mathrm{C}-2=1.5 \pm 0.1$ ), which supports the idea of orientation-conserved substrate transfer in the succinyl-CoA-malate span of the citric acid cycle, as suggested previously [30-32]. However, we cannot exclude the possibility of the existence of unknown metabolic pathways in the rat heart which preferentially convert $\left[3-{ }^{13} \mathrm{C}\right]$ propionate to [3${ }^{13} \mathrm{C}$ ]aspartate. There are data suggesting that propionate can be oxidized through the methylcitrate pathway, at least in Saccharomyces cerevisiae [33], which would also give preferential labelling in pyruvate C-3 and so in aspartate C-3. However, our previous data [32] provided evidence against a metabolically significant methylcitrate pathway in the rat, or any direct conversion of propionate to pyruvate. In addition, an isotope labelling pattern supporting orientation-conserved transfer was also observed by using other substrates (such as acetate and glutamate) both in rats [32] and in Saccharomyces cerevisiae [31]. 
Support for this research was provided by grants OTKA T5057, T006018 anid T006360 from the Hungarian Science Foundation, and from the Ministry of Health ETT, T:06-629/93 (to B.S.).

\section{REFERENCES}

1 Saddik, M. and Lopaschuk, G. D. (1992) J. Biol. Chem. 267, 3825-3831

2 Drake, A. J., Haines, J. R. and Noble, M. I. M. (1980) Cardiovasc. Res. 14, 65-72

3 Williamson, J. R. (1962) Biochem. J. 83, 377-383

4 Saddik, M. and Lopaschuk, G. D. (1991) J. Biol. Chem. 266, 8162-8170

5 Newsholme, E. A., Randle, P. J. and Manchester, K. S. (1962) Nature (London) 193 270-271

6 Kerbey, A. L., Randle, P. J., Cooper, R. H., Whitehouse, S., Pask, H. T. and Denton, R. M. (1976) Biochem. J. 154, 327-348

7 Sherry, A. D., Malloy, C. R., Zhao, P. and Thompson, J. R. (1992) Biochemistry 31, 4833-4837

8 Malloy, C. R., Thompson, J. R., Jeffrey, F. M. H. and Sherry, A. D. (1990) Biochemistry 29, 6756-6761

9 Sumegi, B., Butwell, N. B., Malloy, C. R. and Sherry, A. D. (1994) Biochem. J. 297, 109-113

10 Peuhkurinen, K. J., Hiltunen, J. K. and Hassinen, I. E. (1983) Biochem. J. 210, 193-198

11 Wolfe, R. R., Jahnoor, F. and Mioyoshi, H. (1988) Am. J. Physiol. 254, E532-E535

12 Zhao, P., Sherry, A. D., Malloy, C. R. and Babcock, E. E. (1992) FEBS Lett. 303, 247-250

13 Rona, G. (1985) J. Mol. Cell. Cardiol. 17, 291-306

14 Vertesi, C., Knopf, E., Gaal, J. and Kormoczy, P. S. (1991) J. Cardiovasc. Pharmacol. 17, $\mathrm{S} 141-\mathrm{S} 144$
15 Freeman, R., Mareci, T. H. and Morris, G. A. (1981) J. Magn. Reson. 42, 341-345

16 Bodenhausen, G. and Ruben, D. J. (1980) Chem. Phys. Lett. 69, 185-188

17 Müller, L. (1979) J. Am. Chem. Soc. 101, 4481-4484

18 Bendall, M. R., Pegg, D. T., Doddrell, D. M. and Field, J. (1983) J. Magn. Reson. 51, $520-526$

19 Malloy, C. R., Sherry, A. D. and Jeffery, F. M. H. (1990) Am. J. Physiol. 259, H987-H995

20 Sherry, A. D., Malloy, C. R., Roby, R. E., Rajagopal, A. and Jeffrey, F. M. H. (1988) Biochem. J. 254, 593-598

21 Galagher, K. P., Osakada, G., Matsuzatki, M., Miller, M., Kemper, W. S. and Ross, J., Jr. (1985) Am. J. Physiol. 249, H241-H248

22 Hoffman, J. I. E. and Spaan, J. A. E. (1990) Physiol. Rev. 70, 331-390

23 Homans, D. C., Sublett, E., Lindstrom, P., Nesbitt, T. and Bache, R. J. (1988) Circulation 78, 1267-1276

24 Weiss, H. R., Neubauer, J. A., Lipp, J. A. and Sinha, A. K. (1978) Circ. Res. 42 , $394-401$

25 Lundsgaard-Hanses, P. and Riedwyl, H. (1967) Eur. J. Physiol. 297, 89-106

26 Paulson, D. J., Shug, A. L. and Zhao, J. (1992) Mol. Cell. Biochem. 116, 131-137

27 Motterlini, R., Samaja, M., Tarantola, M., Micheeletti, R. and Bianchi, G. (1992) Mol. Cell. Biochem. 116, 139-145

28 Hulsmann, W. C. (1991) Cardiovasc. Drugs Ther. 5 (Suppl. 1), 11-16

29 Stryer, L. (1988) Biochemistry, 3rd edn., W. H. Freeman, New York

30 Sumegi, B., Sherry, A. D. and Malloy, C. R. (1990) Biochemistry 29, 9106-9110

31 Sumegi, B., Sherry, A. D., Malloy, C. R. and Srere, P. A. (1993) Biochemistry 32, 12725-12729

32 Sherry, A. D., Sumegi, B., Miller, B., Cottam, G. L., Gavva, S., Jones, J. G. and Malloy, C. R. (1994) Biochemistry 33, 6268-6275

33 Pronk, J. T., van der Linden-Beumer, A., Verduyn, C., Sheffers, W. A. and van Dijken, J. P. (1994) Microbiology 140, 717-722

Received 1 May 1995/26 June 1995; accepted 11 July 1995 